$$
5 \times 1094-157 / 6
$$

Preprint of paper presented at the $1^{\text {st }}$ World Conf. on Photovoltaic Energy Conversion, Waikoloa, Hawaii, 5-9 December 1994.

$$
\text { conf- } 941203--15
$$

\title{
THE EFFECT OF ENCAPSULATION ON THE REFLECTANCE OF PHOTOVOLTAIC MODULES USING TEXTURED MULTICRYSTALLINE-SILICON SOLAR CELLS
}

\author{
James M. Gee, W. Kent Schubert, Herbert L. Tardy, \\ and Thomas D. Hund \\ Photovoltaic System Components Department \\ Sandia National Laboratories \\ Albuquerque, NM 87185-0752
}

\author{
Gary Robison \\ Semiconductor Assembly Network \\ 7061 Fox Circle \\ Prescott Valley, AZ 86314
}

\begin{abstract}
Texturing multicrystalline-silicon cells is a promising technique for reducing reflectance losses. We investigated two methods for texturing multicrystalline-silicon solar cells - anisotropic chemical etch and mechanical dicing saw. Our work emphasized reducing reflectance in the encapsulated module by using optical confinement in the module. We found that optical confinement in the module is very important in the optimization of texture geometries.
\end{abstract}

\section{INTRODUCTION}

Reflectance control is a major issue for multicrystalline-silicon (mc-Si) photovoltaic (PV) modules. Single-crystal silicon (sc-Si) cells commonly use anisotropic etches to form a textured surface to reduce surface reflectance. These anisotropic etches are less effective with $\mathrm{mc}-\mathrm{Si}$ substrates because the grains have random crystal orientations. Hence, most commercial mc-Si PV modules use cells with planar surfaces. The planar surfaces of commercial mc-Si cells reduce the efficiency of mc-Si modules by about $1.5 \%$ absolute compared to commercial sc-Si modules with textured cells [1].

Several research groups have recently proposed texturing mc-Si by mechanical methods, e.g., dicing wheels and saws. Mechanical texturing can achieve minimum throughput requirements for commercial production with special tooling, and several research groups recently demonstrated very low reflectances and high-efficiency mc-Si cells with mechanical texturing $[2,3,4]$. These researchers used commercial dicing saws with a single blade, so the throughput was very low. These reports also did not optimize the texture geometry for encapsulation. Chemical texturing of $\mathrm{mc}-\mathrm{Si}$ with anisotropic etches has also been reported [5].

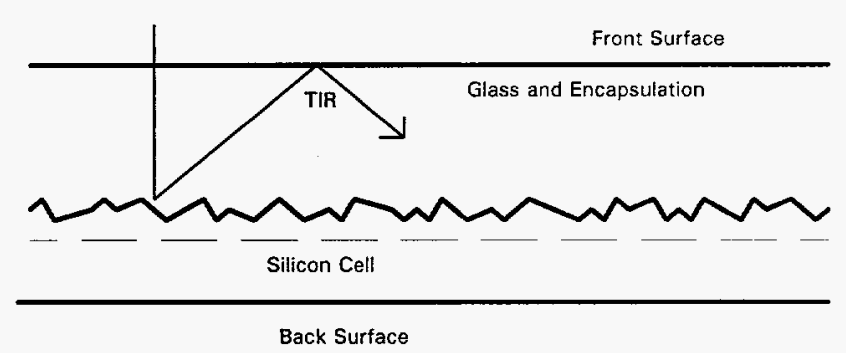

Figure 1. Illustration of optical confinement in one-sun photovoltaic modules. The scattering surface can either be a solar cell with a textured surface or a coating deposited on a planar silicon cell with a high refractive index.
Solar cells are typically encapsulated into photovoltaic modules for environmental stability. Several researchers have noted that the effective reflectance at the encapsulation-solar cell interface can be significantly reduced in a PV module by promoting optical confinement of light reflected from the solar cell surface in the module encapsulation $[1,5,6,7]$. However, this principle has not been previously applied to textured mc-Si cells.

This paper examines optimization of mechanically textured mc-Si substrates for use in an encapsulated module. A key finding of our study is that relatively shallow texture geometries have acceptable reflectance characteristics. This paper begins with a description of optical confinement in PV modules. We next present two optical models of flat-plate PV modules with textured-silicon cells. We briefly discuss our mechanical- and chemical-texture techniques for mc-Si, including preliminary development of high-throughput tooling for mechanical texturing. We conclude the paper with characterization of chemically and mechanically textured, encapsulated mc-Si samples.

\section{OPTICAL CONFINEMENT IN PHOTOVOLTAIC MODULES}

Textured surfaces can reduce reflectance in PV modules by two methods. The first method reduces reflectance at the textured-silicon surface by forcing the incident ray to strike the textured surface two or more times before reflecting from the surface. For uniform pyramids or grooves, the texture angle must be greater than $30^{\circ}$ to experience any double-bounce reflectance. (Texture angle is the angle between the horizontal and the texture surface.) More rays experience multiplebounce reflectance at steeper texture angles, so that minimization of reflectance favors steeper texture angles. Steep texture angles place more severe requirements on the mechanical texture tooling and produce difficult surface geometries for processing.

The second method that a textured surface can reduce reflectance in a PV module is by optical confinement of scattered rays in the module encapsulation (Figure 1). Optical confinement refers to confinement of rays in a material with a high refractive index at an interface with a material with a lower refractive index due to total internal reflection [8]. In PV modules, the rays reflected from the solar cell surface can experience total internal reflection at the glass-air interface if the reflecting surface scatters the direction of the rays (Figure 1). The net result of optical confinement is to reduce the effective reflectance at the encapsulation-solar cell interface. For glass encapsulation with a refractive index of 1.5 , the texture angle only needs to be greater than $22.5^{\circ}$ to obtain optical confinement $[7]$.

This work was performed by Sandia National Laboratories for the US Department of Energy under contract DE-AC04-94AL85000. 


\section{DISCLAIMER}

Portions of this document may be illegible in electronic image products. Images are produced from the best available original document. 


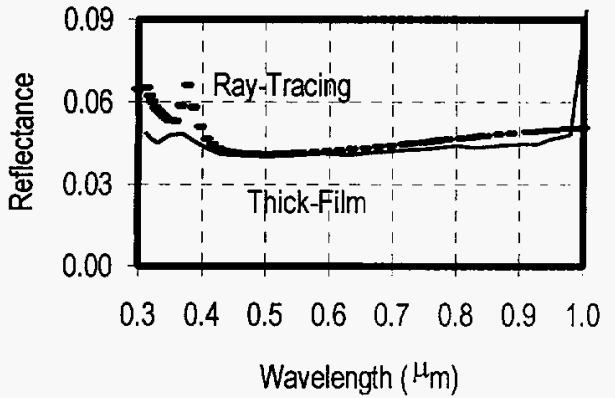

Figure 2. Comparison of ray-tracing and thick-film model. The model calculations assumed a texture angle of $30^{\circ}$ and a slat geometry.

\section{OPTICAL MODELS}

We used two optical models to examine the reflectance of PV modules with textured silicon cells. The first model uses a ray-tracing numerical model developed by Smith and Rohatgi [9]. This model is rigorously accurate in the simulation, but is limited in the types of surface geometry that can be simulated.

The second model is a simple thick-film optical model of the PV module. This model requires some assumptions to simulate the optical confinement in the module encapsulation. We only considered a slat geometry for mechanically textured surfaces because this geometry can be scribed in a single pass of the mechanical scriber. A simple two-dimensional ray-tracing plot shows that most light is coupled out of the module after two passes with uniform grooves. (Uniform grooves have the same texture angle on both surfaces of the groove.) We assumed that light is fully coupled out after two passes for textured cells with a slat geometry in our thick-film optical model. The only adjustable parameter in this model is the reflectance at the glass-air interface after the first pass, which is proportional to the fraction of reflected light that is not scattered at the encapsulation-solar cell interface.

A thick-film optical model of chemically textured mc-Si cells is more complicated due to the spatial non-uniformities of the texture. There are at least two adjustable parameters in a model of chemically textured mc-Si. Firstly, the model must account for the fraction of grains that are sufficiently textured to obtain optical confinement. Secondly, the effective encapsulation-cell reflectance of the textured grains is not known a priori because the textured grains will exhibit a range of reflectances - e.g., the orientation and texture on some grains may produce "double-bounce" reflectance, while other grains with singlebounce reflectance might trap the light for two passes or for four passes.

Figure 2 presents a comparison of the detailed ray-tracing model with our simple optical model for the slat geometry. We used a front-surface internal reflectance of $100 \%$ for this comparison. The good correlation between the two models validates the assumptions of our simple model. We use the ray-tracing model for design of texture geometries, and use the thick-film model for fitting of experimental data.

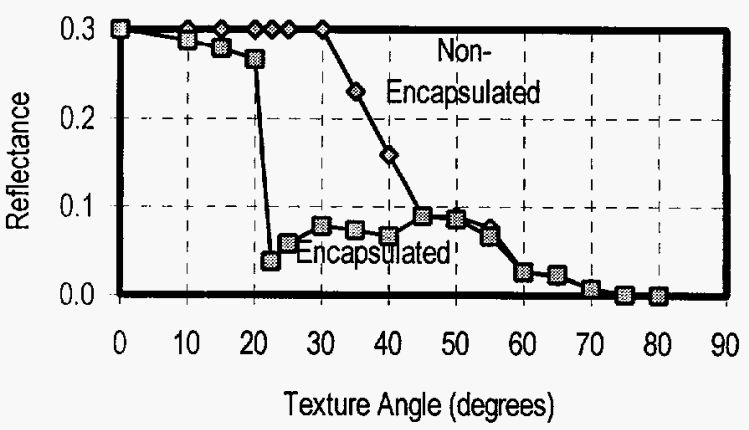

Figure 3. Effect of texture angle on reflectance of textured silicon cells with a slat geometry. There is no antireflection coating on the silicon cell and the air-glass reflectance was set to 0 .

\section{DESIGN OF MECHANICALLY TEXTURED mC-SI SURFACES}

We used our ray-tracing model to examine the design of mechanically textured mc-Si surfaces (Figure 3). These simulations examined silicon cells with uniform grooves. These simulations used no antireflection coating on the silicon cell and the air-glass reflectance was set to zero to highlight the effect of the texture geometry. Note that the simulated encapsulated reflectance is therefore equal to the effective reflectance at the encapsulation-solar cell interface. We found that very significant reductions in the encapsulated reflectance are achieved at a texture angle of only $22.5^{\circ}$. This reduction of reflectance is due to confinement of rays in the module by total internal reflection at the glass-air interface (Figure 1). Note that a texture angle of $45^{\circ}$ would be required to obtain the same reflectance without the optical benefits due to the encapsulation.

Wenham et alia examined a very similar problem - encapsulated silicon cells with grooves formed by (111) planes [6]. They found that the optical confinement in the module could be improved even further by using non-uniform grooves. Proper design of the non-uniform grooves confine the rays in the module for at least four passes, which would further reduce the effective reflectance at the encapsulation-solar cell interface.

Our simulations considered only normal incidence. Most PV modules are used in a fixed configuration or with single-axis tracking where the position of the sun relative to the normal of the module varies continuously. Campbell, Wenham, and Green considered oblique incidence for a similar problem of grooved surfaces with tilted (111) planes; these authors found acceptable performance for non-normal incidence when the groove axis is aligned with the solar trajectory [10].

\section{PREPARATION OF TEXTURED MG-Si SAMPLES}

A major limitation of mechanical texture tooling developed to date is throughput; typically, a dicing saw was used with a single blade, which could require up to 40 minutes to mechanically texture a $100-\mathrm{cm}^{2}$ slice. Semiconductor Assembly Network (SAN) developed a multiblade tool for use with a commercial dicing saw [11]. The multiblade tool consisted of 10 stacked, beveled, $90-\mu \mathrm{m}$ blades. The number of blades was limited to 10 blades due to mechanical limitations of the commercial dicing saw. The cutting speed and effective throughput were $90 \mathrm{~mm} / \mathrm{s}$ and 10 slices per hour, respectively. 


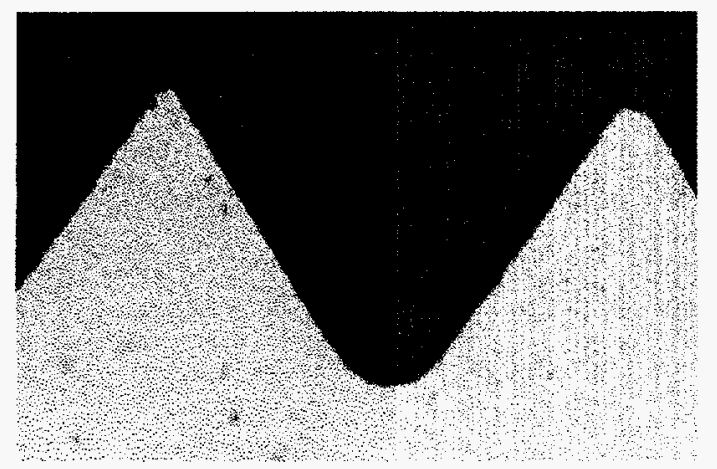

Figure 4a. Photomicrograph of as-textured, mechanicaily textured surface. The grooves have a spacing of $90 \mu \mathrm{m}$.

We believe that an optimized machine would use a monolithic tool rather than stacked blades, and would texture a $100-\mathrm{cm}^{2} \mathrm{mc}-\mathrm{Si}$ slice in a single pass. SAN projected the following for an optimized machine with a monolithic tool for cutting $45^{\circ}$ grooves [11]:

- a throughput between 100 and 250 slices per hour

- a blade lifetime of $1200 \mathrm{~m}\left(12,500100-\mathrm{cm}^{2}\right.$ slices $)$

- equipment cost between $\$ 175 \mathrm{~K}$ and $\$ 220 \mathrm{~K}$ per machine

- blade cost of $\$ 2.2 \mathrm{~K}$ and resharpening cost of $\$ 1 \mathrm{~K}$

- a net scribing cost per wafer between 0.10 and 1.00 \$/slice

We prepared some mechanically textured, mc-Si and sc-Si (Czochralski - Cz) samples to test our optical models. The mc-Si samples were grown using the Heat Exchanger Method (HEM) by Crystal Systems. These samples were textured with the stacked beveled blades by SAN. We then etched these samples in a 15:1 nitric:hydrofluoric acid solution for 3 minutes to remove residual damage from the mechanical texturing. The samples had a texture angle around $45^{\circ}$ and $32^{\circ}$ before and after the etch, respectively. The texture angle was severely degraded by the chemical etch, which may be related to increased etching rates at the groove tips (Figure 4).

We also prepared some chemically textured mc-Si samples using HEM and Edge-defined Film-fed Growth (EFG) material from ASE Americas (formerly Mobil Solar). Chemical texturing using potassium- or sodiumhydroxide solutions is a well-known technique that is widely used in ScSi solar cells [12]. Chemical texturing probably has a lower cost per slice than mechanical texturing, so comparing the performance of mechanical and chemical texturing is of interest. We used a solution of 125:2:5 of deionized water:potassium hydroxide:isopropyl alcohol at $70^{\circ} \mathrm{C}$. We found that 5-, 10 -, and 15 -minute etches produced similar reflectance characteristics on the HEM material. Due to the random crystal orientation of the grains, some grains etch more rapidly than other grains. Hence, a shorter etch is preferred to avoid large step heights at grain boundaries.

\section{CHARACTERIZATION OF TEXTURED MC-Si SAMPLES}

We measured the hemispherical reflectance of the textured samples both prior to and after encapsulation. Half of each sample received a single-layer antireflection (SLAR) coating of evaporated $\mathrm{TiO}_{2}$. We then calculated the solar-weighted reflectance of each sample (Table 1). In order to emphasize differences due to changes in the encapsulationcell reflectance, the solar-weighted reflectance calculation only used the spectrum between 300 and $1000 \mathrm{~nm}$. (The reflectance spectra for wavelengths greater than $1000 \mathrm{~nm}$ are affected by reflectance of the back surface of the silicon sample.)

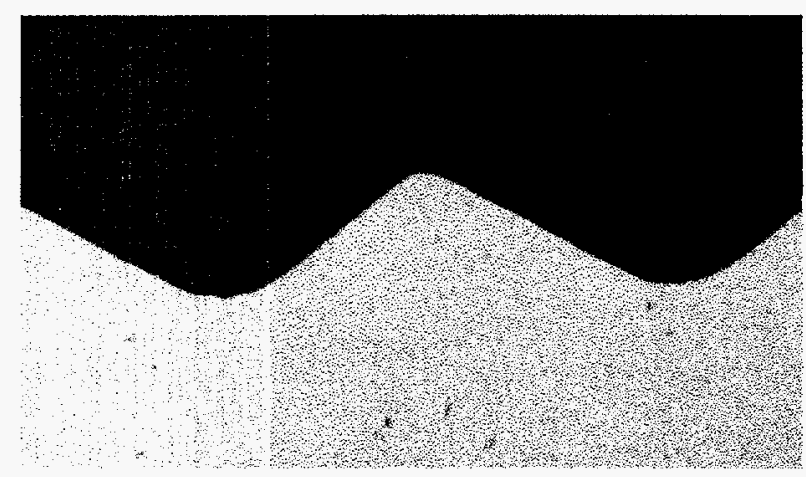

Figure $4 \mathrm{~b}$. Photomicrograph of mechanically textured surface after a chemical etch.

We used our thick-film optical model to examine the reflectance of the encapsulated, mechanically textured, $\mathrm{Cz}$ sample (Figure 5). We found that a front-surface internal reflectance of $50 \%$ matched the measured data, which implies that only $50 \%$ of the rays reflected from the silicon surface experienced total internal reflection at the glass-air interface. All the rays reflected from $30^{\circ}$ grooves should experience total internal reflection; the reduced reflectance is due to the rounded bottoms on the grooves (Figure 4).

We also used our thick-film optical model to investigate the chemically textured, mc-Si reflectance spectra. By both visual inspection and through optical modeling, we found that the approximately $50 \%$ of the grains are sufficiently textured to obtain reflectance reduction through optical confinement. We also found that the effective reflectance at the encapsulation-cell interface for the textured grains was equivalent to two passes of double-bounce and/or four passes of single-bounce reflectance. Since only a few of the grains have upright pyramids with double-bounce reflectance, this observation is an indirect confirmation of the theoretical prediction by Wenham et alia that tilted (111) pyramids lead to superior optical confinement [6]. An interesting observation is that the non-textured grains appear to be "polished" by the texture etch; grains with orientations near (111) or (110) are probably planarized by the anisotropic etch.

We were unable to fabricate cells with the mechanically textured mc-Si material because the surface features were too large to be processed with our photolithography processes (Figure 4). We were able to process cells with the chemically textured mc-Si material, and we used chemical texturing for fabrication of large-area $16 \%$-efficient mc-Si cells

Table 1. Calculated solar-weighted reflectance $\langle\mathrm{R}\rangle$ of encapsulated, textured-silicon samples with and without a single-layer antireflection coating (Bare and SLAR). The samples were all chemically textured except MechT, which was mechanically textured. The data is the average for several samples.

\begin{tabular}{|c|c|c|c|}
\hline \multirow[t]{2}{*}{ Material } & \multirow[t]{2}{*}{ Text } & \multicolumn{2}{|c|}{$\langle R>(\%)$} \\
\hline & & Bare & SLAR \\
\hline $\mathrm{Cz}$ & $Y$ & 7.1 & 4.9 \\
\hline EFG & $\mathrm{N}$ & 21.0 & 7.2 \\
\hline EFG & $Y$ & 15.8 & 7.0 \\
\hline HEM & $N$ & 14.8 & 7.2 \\
\hline HEM & $Y$ & 13.4 & 6.4 \\
\hline MechT & $Y$ & 11.2 & 5.7 \\
\hline
\end{tabular}




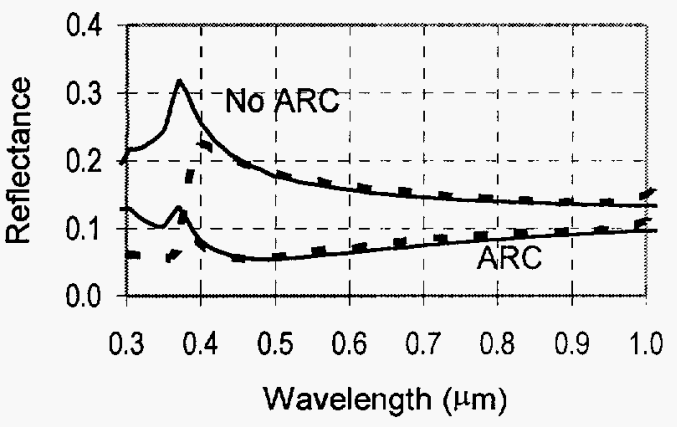

Figure 5. Comparison of model calculations (solid) with the measured hemispherical reflectance (dashed) of encapsulated, mechanically textured, mc-Si samples with and without a $\mathrm{TiO}_{2}$ antireflection coating.

for our recent demonstration of a $15 \%$-efficient mc-Si module [13] Chemical texturing of $\mathrm{mc}-\mathrm{Si}$ cells reduced the solar-weighted encapsulated reflectance by $50 \%$ compared to planar cells (Figure 6).

\section{SUMMARY}

We presented the results of an experimental and theoretical investigation of mechanical- and chemical-texture techniques for $\mathrm{mc}-\mathrm{Si}$ material. We obtained low solar-weighted refiectances for both chemically and mechanically textured, encapsulated mc-Si samples using texture processes with reasonable throughputs.

There are two important results from this work. Firstly, we found that optical confinement of scattered rays is an important phenemon in flatplate PV modules. Optical confinement was found to be very important for reducing the reflectance of all the encapsulated, textured mc-Si samples in this study. We even found that optical confinement affects the encapsulated reflectance of some nominally planar samples. For example, the planar HEM samples of Table 1 had an entirely diffuse reflectance characteristic prior to encapsulation, which is probably due to small-scale texture from the slicing operation. The reflectance of these encapsulated, planar HEM samples were nearly as low as the reflectance of the encapsulated, chemically textured, HEM samples (Table 1) due to the optical confinement of rays scattered from the small-scale texture.

The second important result from this work is that relatively shallow texture angles yield acceptable results for mechanically textured, $\mathrm{mc}-\mathrm{Si}$ cells. The use of shallow texture angles, possibly combined with nonuniform groove geometries, is an important result because the tooling and processing for mechanical texturing may be less expensive and have better throughput with shallower texture angles. As an example, preliminary projections by SAN for $30^{\circ}$ grooves indicates that the cost of the mechanical grooving step could be reduced by one-half compared to machining $45^{\circ}$ grooves [14]. Similarly, with the relaxed requirements on texture geometries, other texturing methods could be considered.
Encapsulated Multicrystalline-Silicon Cells

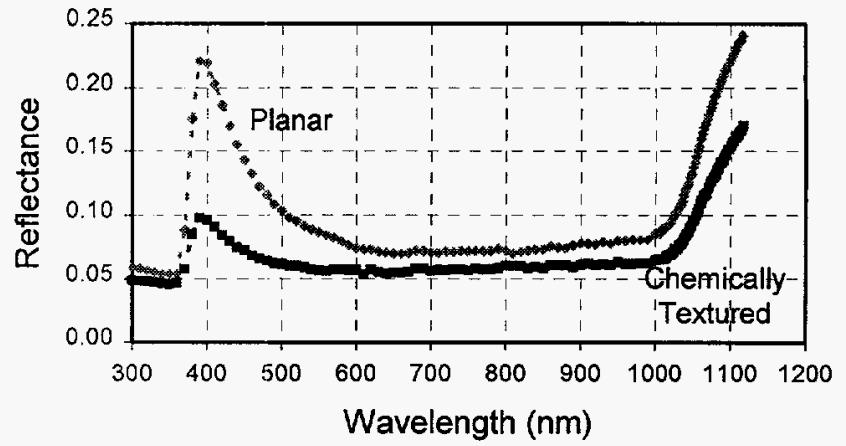

Figure 6. Hemispherical reflectance of encapsulated, mc-Si solar cells. The solar-weighted reflectance of the planar and textured cells are $9 \%$ and $6 \%$, respectively. These cells have a $\mathrm{TiO}_{2} / \mathrm{Al}_{2} \mathrm{O}_{3}$ doublelayer antireflection coating

\section{ACKNOWLEDGMENTS}

M. E. Buck, J. W. Tingley, and B. L. Silva processed many of the samples, and L. W. Inwin performed the reflectance measurements.

\section{REFERENCES}

PVSC refers to IEEE Photovoltaic Specialists Conference, and PVSEC refers to International Photovoltaic Science and Engineering Conference.

1. J. M. Gee, et alia, "Reflectance control for multicrystalline-silicon photovoltaic modules using textured-dielectric coatings," in this conference

2. H. Bender, ef alia, Appl. Phys. Lett. 62, 2941 (1993).

3. H. Nakaya, et alia, PVSEC-7, Nagoya, Japan, pp. $91-92$ (1993).

4. J. Szlufcik, et alia, 12 ${ }^{\text {th }}$ Eur. Photo. Solar Energy Conf., pp. 769$772(1994)$

5. B. L. Sopori, Solar Cells 28, pp. 253-260 (1990).

6. S. R. Wenham, et alia, 22nd PVSC, pp. 105-110 (1991).

7. P. Jenkins, et alia, Solar Energy Materials and Solar Cells 33, pp. 125-133 (1994).

8. E. Yablonovitch and G. C. Cody, IEEE Trans. Elect. Dev. ED-29, pp. 300-305 (1982).

9. A. W. Smith, A. Rohatgi, and S. C. Neel, 21 st PVSC, pp. 426-431 (1990).

10. P. Campbell, S. R. Wenham, and M. A. Green, PVSEC-4, pp. 615$620(1989)$

11. G. Robison, final report on contract AF-8900, Sandia National Laboratories (October 1994).

12. D. L. King and M. E. Buck, 22 nd PVSC, pp. 303-308 (1991).

13. D. L. King, et alia, "World's First 15\%-Efficient MulticrystallineSilicon Module," in this conference.

14. G. Robison, private communication (November 1994).
This report was prepared as an account of work sponsored by an agency of the United States Government. Neither the United States Government nor any agency thereof, nor any of their employees, makes any warranty, express or implied, or assumes any legal liability or responsibility for the accuracy, completeness, or usefulness of any information, apparatus, product, or process disclosed, or represents that its use would not infringe privately owned rights. Reference herein to any specific commercial product, process, or service by trade name, trademairk, manufacturer, or otherwise does not necessarily constitute or imply its endorsement, recommendation, or favoring by the United States Government or any agency thereof. The views and opinions of authors expressed herein do not necessarily state or reflect those of the United States Government or any agency thereof. 